\title{
Redes Ambientales de Políticas Públicas: enfoque alternativo para el turismo en el Parque Nacional Nevado de Toluca - México
}

\author{
Redes Ambientais de Políticas Públicas: um enfoque alternativo para o turismo no Parque \\ Nacional Nevado de Toluca - México
}

Environmental networks of public policies: an alternative approach for tourism in Nevado de Toluca National Park - Mexico

Rafael Fernando Sánchez Barreto ${ }^{1}$

Rocío del Carmen Serrano Barquín ${ }^{2}$

Graciela Cruz Jiménez ${ }^{3}$

\section{Resumen}

Las redes sociales, conceptualizadas como el conjunto de relaciones personales y colectivas en torno a un problema público, han sido examinadas para explicar el vínculo entre diversos actores sociales y su rol en la sociedad; sin embargo, en el Estado de México poco se ha avanzado en su estudio como estructuras y oportunidades que permitan dar solución a problemas ambientales, particularmente relacionadas con el turismo en áreas naturales. Mediante el trabajo documental y de campo; además de la utilización de técnicas como la observación participante y la aplicación de entrevistas, se logró diseñar un modelo teóricometodológico en el cual las redes ambientales de políticas públicas se convierten en una alternativa para impulsar la práctica de la actividad turística en el Parque Nacional "Nevado de Toluca".

Palabras clave: Redes sociales, política pública, turismo, áreas naturales protegidas.

\section{Resumo}

As redes sociais conceptuadas como um conjunto de relações pessoais e coletivas sobre um problema público têm sido revisadas para explicar o vínculo entre os diversos atores sociais e os seus "roles" na sociedade. Entretanto, no Estado de México pouco são os avanços no estudo como estruturas e oportunidades que possibilitem dar as soluções aos problemas ambientais, particularmente relacionados com o turismo nas áreas naturais. Através do

\footnotetext{
${ }^{1}$ Doutorado em Estudos Turísticos pela Universidad Autónoma del Estado de México (UAEMéx). Professor da Faculdade de Turismo e Gastronomia da UAEMex México. E-mail: rfsanchezb@uaemex.mx

${ }^{2}$ Doutorado em Ciências Ambientais pela UAEMéx. Profesora da Faculdade de Turismo e Gastronomia da UAEMéx. México. E-mail: rocioserba@yahoo.com.mx.

${ }^{3}$ Doutorado em Ciencias Sociais pelo Colegio Mexiquense. Profesora da Faculdade de Turismo e Gastronomia da UAEMéx. México. E-mail: gracicj@ hotmail.com.
} 
estudo documental e de campo, além da utilização de técnicas como a observação participativa e a aplicação de entrevistas, desenhou-se um modelo teórico-metodológico no qual as redes ambientais de políticas públicas se tornaram uma alternativa para fomentar a práctica da atividade turística no Parque Nacional "Nevado de Toluca".

Palavras-chave: redes sociais, políticas públicas, turismo, áreas naturais protegidas.

\begin{abstract}
Social networks, conceptualized as the set of personal and collective relationships around a public problem, have been examined in order to explain the link between various social actors and their role in society; however, in the State of Mexico, Mexico, there is scarce advancement in studying them as structures and opportunities that allow solving environmental issues, in particular those related to tourism in natural areas. By means of documentary and in-field work, in addition to the utilization of techniques, such as participant observation, and holding interviews, we managed to design a theoretical-methodological model in which the environmental networks of public policies turn into an alternative to foster the practice of touristic activities in "Nevado de Toluca" National Park.
\end{abstract}

Key words: social networks, public policy, tourism, protected natural areas.

\title{
1. Presentación
}

Las redes sociales, como colectivo de personas con un interés por dar solución a una problemática en particular, se presentan como un tema recurrente en textos e investigaciones que sobre políticas públicas han abordado distintos autores (Rhodes, 1997; Cruz, 2008; Porras, 2012). Cada vez, nuevos enfoques relacionados con la participación ciudadana se hacen patentes a partir de la necesidad de abordar distintas problemáticas, entre las que destacan las ambientales.

Recientemente, en el Estado de México, la conformación de este tipo de colectivos en materia ambiental ha despegado de tal manera que entre los años 2010-2012, 51 grupos y 18 ambientalistas independientes (Mejía Alonso, 2012), se unieron para integrar una red denominada Red de Ambientalistas del Estado de México (REDAEM), para empezar a diseñar las estrategias de presión ante el gobierno por un ambiente sano. Uno de los puntos torales que preocupa y ocupa a la red, se refiere a la recuperación del Parque Nacional "Nevado de Toluca", de suma importancia ecológica regional debido a los servicios ambientales que proporciona y que lo identifican como un reservorio de biodiversidad; un área natural de recarga, drenado y regulación de acuíferos del bosque (Vigliani, 2009), de bióxido de carbono, así como liberación de oxígeno, 
además de representar un atractivo que es aprovechado por el turismo debido al paisaje, la tranquilidad y la presencia de nieve en algunos periodos.

Esta área natural protegida ${ }^{4}$, es el cuarto pico más alto en México, localizado a 23 kilómetros al suroeste de la ciudad de Toluca, también llamado Xinantécatl, que significa "hombre desnudo". Tiene como límite la cota de los 3000 msnm; su mayor elevación está en el Pico del Fraile a los 4 660 msnm; descansa sobre una formación de rocas calcáreas del cretácico con edad del plioceno al pleistoceno (hace unos 30000 años). El parque nacional ocupa una superficie de 53912 hectáreas, correspondientes a 11 municipios: Almoloya de Juárez, Amanalco de Becerra, Calimaya, Coatepec de Harinas, Temascaltepec, Tenango del Valle, Texcaltitlán, Toluca, Villa Guerrero, Villa Victoria y Zinacantepec (CONANP, 2008: 13), (Pérez-Ramírez, et al., 2009).

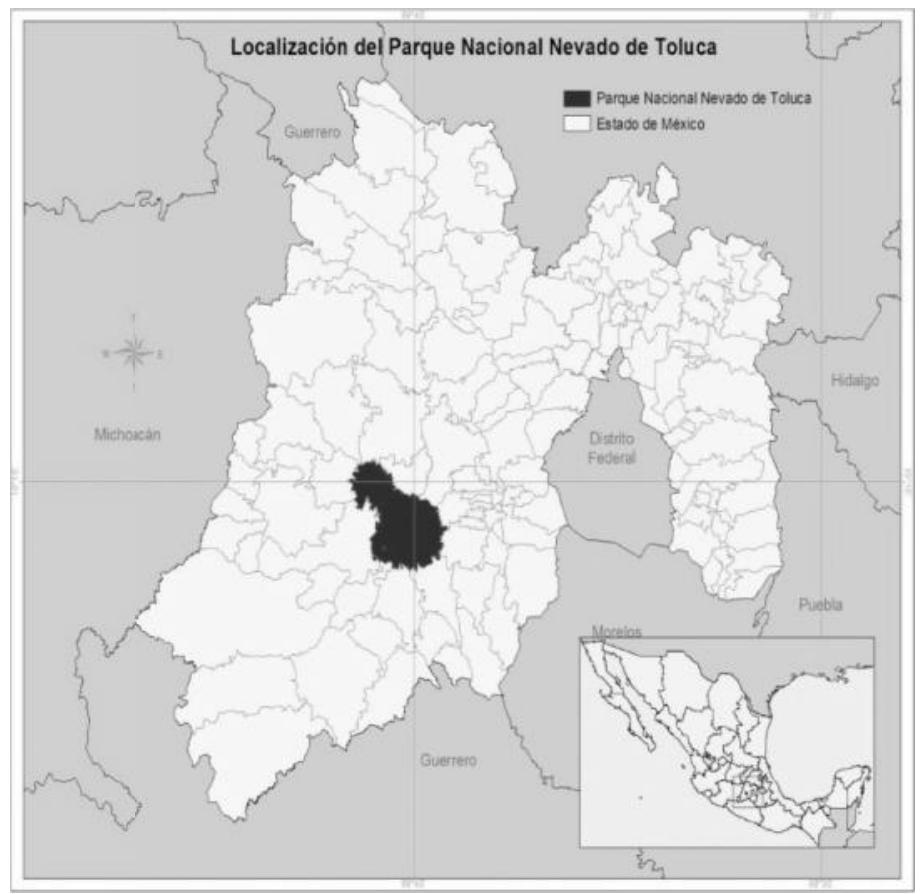

Mapa 1. Ubicación del Parque Nacional "Nevado de Toluca" Fuente: CONANP, 2008

\footnotetext{
${ }^{4}$ En México, las áreas naturales protegidas se consideran como las zonas del territorio nacional y aquéllas sobre las que la nación ejerce su soberanía y jurisdicción, en donde los ambientes originales no han sido significativamente alterados por la actividad del ser humano o que requieren ser preservadas y restauradas y están sujetas al régimen previsto en la Ley General del Equilibrio Ecológico y Protección al Ambiente y su reglamento en materia de áreas naturales protegidas (LGEEPA, 1988).
} 
No obstante ello, actualmente el "Nevado de Toluca", presenta serios impactos ambientales debido a cambios de uso de suelo resultado de la presión antrópica, dado el continuo crecimiento de las actividades agrícolas, pecuarias y recreativas; a la tala inmoderada y clandestina, la disposición inadecuada de residuos sólidos; la apertura de minas y los asentamientos humanos descontrolados. Además de estos factores locales, se puede mencionar un impacto global como lo es el cambio climático. Este deterioro se refleja en la disminución de la biodiversidad, el incremento de plagas y enfermedades (Franco et al., 2009).

Desde la creación del Parque en 1936, dichos impactos han mermado la vegetación de más de 53000 hectáreas, de las cuales 17000 correspondientes a algunos estratos, presentan algún tipo de plaga; además de que está en riesgo la fauna nativa como el tecolotito serrano, el conejo teporingo y el venado cola blanca (CONANP, 2008: 92). A lo anterior, hay que sumar los azolves e inundaciones en las partes bajas debido a la erosión generada por los residuos de agroquímicos de las tierras agrícolas, de las grandes cantidades de materiales provenientes de minas ubicadas en las áreas aledañas al parque nacional, así como la "basura" que se deposita en los cauces que debido a los cambios en los regímenes térmico y pluvial intensifican los problemas planteados. Ante esta situación, el gobierno estatal ha manifestado el interés por llevar a cabo diversas acciones con respecto a esta área natural protegida, entre las que se encuentran la recategorización ${ }^{5}$ del parque nacional (Ceballos, 2010; UAEM, 2013).

En este contexto, el objetivo del artículo consiste en analizar y caracterizar desde la perspectiva de las redes sociales, a la Red de Ambientalistas del Estado de México, partiendo de la teoría de los sistemas complejos, así como de la metodología de redes de política pública, que permita abordar al turismo como lo que representa, una actividad que busca la armonía entre las acciones derivadas de la oferta de alternativas de esparcimiento, de conservación de áreas naturales, así como de desarrollo de las comunidades locales (Serrano Barquín, 2008). Para ello, el artículo se organiza en distintos apartados entre los que se abordan principalmente: consideraciones metodológicas, conceptualización y tipología de las

\footnotetext{
${ }^{5}$ La recategorización que se plantea, implica modificar el status de Parque Nacional con que se identifica actualmente el área natural del "Nevado de Toluca", al de Reserva de Protección de Flora y Fauna. Este cambio no está claro y a decir de autoridades de la Secretaría del Medio Ambiente y Recursos Naturales federal, se sustenta en que en el decreto de 1936, por una parte no se especificó el área a proteger y por la otra, existe la necesidad de implementar estrategias de aprovechamiento de los recursos naturales que permita a las comunidades locales tener beneficios económicos derivados del manejo de los mismos.
} 
redes sociales, redes ambientales en México, turismo en el Parque Nacional "Nevado de Toluca", modelo de análisis de una red ambiental de política pública para el desarrollo del turismo en el Parque Nacional "Nevado de Toluca", conclusiones y referencias.

\section{Consideraciones Metodológicas}

Con la finalidad de acceder a la información de distintas fuentes, primarias y secundarias para contextualizar la investigación, la metodología considerada implicó dos fases: la exploración documental y de campo. Referente a la primera, se consultaron diversas fuentes bibliográficas y hemerográficas, tomando como ejes de análisis los temas centrales de la investigación (redes de política pública, redes ambientales, turismo y áreas naturales protegidas). Con respecto a la segunda, entre los años 2010 y 2012, se realizaron visitas al Parque Nacional Nevado de Toluca, en donde mediante la observación participante y el uso de equipo fotográfico y de cómputo (Flick, 2007), se obtuvo y procesó información para sustentar la base empírica de la investigación.

Para resaltar el enfoque cualitativo de la investigación, entre los años 2010 y 2012, se aplicaron una serie de entrevistas semiestructuradas (Hernández Sampieri, et al., 2010; Pérez Andrés, 2002), dirigidas a informantes clave. La determinación de la muestra para elegir a dichos informantes, consideró principalmente dos rubros: autoridades gubernamentales relacionadas con el manejo del Parque Nacional, así como la comunidad local encargada de la administración del Parque de Los Venados; e, individuos y grupos ambientales pertenecientes a la REDAEM.

Respecto de las autoridades gubernamentales, se tuvo la oportunidad de analizar tanto con el Biól. Luis Miguel Mandujano Álvarez, Director del Parque Nacional "Nevado de Toluca", como con el Ing. Salomón Montoya, integrante de la Comisión Estatal de Áreas Naturales y de la Fauna (CEPANAF), organismo regulador de áreas naturales en el Estado de México, lo relacionado a la situación de deterioro ambiental del Parque, así como lo correspondiente a la factibilidad de las comunidades locales para el desarrollo de proyectos de turismo, sobre todo de naturaleza.

El acercamiento con la comunidad local, se dio a través del Sr. Efrén Ramírez Godínez, Comisariado Ejidal de San Juan de las Huertas, Municipio de Zinacantepec, lugar donde se 
ubica el Parque de Los Venados, uno de los principales atractivos para el turismo en el "Nevado de Toluca".

Como parte de la Dirección de Turismo del Ayuntamiento de Toluca, se conversó con el Lic. Eduardo Reyes Piza, quien como promotor de turismo, fue un referente para conocer y reconocer la política turística municipal y por tanto de la visión que desde la alcaldía de la capital del Estado de México se tiene sobre la situación del "Nevado de Toluca".

Cabe hacer mención que referente a los grupos ambientales, se asistió a las seis reuniones convocadas por la REDAEM, lo cual permitió conocer e identificar a individuos y grupos ambientales vinculados de alguna manera en actividades de protección, conservación, y restauración del Parque Nacional "Nevado de Toluca".

Entre los individuos y grupos que llevan a cabo acciones ambientales en el área natural y con lo cuales se tuvo la oportunidad de analizar tanto la situación del deterioro ambiental del Parque como las posibilidades de desarrollo del turismo, se encuentran: el Dr. Isaías de la Rosa, ambientalista, representante del Instituto Tecnológico de Toluca y principal promotor de la recuperación del "Nevado de Toluca"; la Ing. Angélica Hernández García, ambientalista, promotora de programas de conservación de fauna y productora orgánica en las inmediaciones del "Nevado de Toluca"; el Prof. Francisco Mejía Alonso, Presidente de la Red de Ambientalistas del Estado de México y uno de los pilares de la participación social en temas ambientales en el Estado de México; además del C. Pedro Pliego Castil, presidente de Red Acción Ambiente, uno de los grupos ambientales que más tiempo tienen trabajando en el "Nevado de Toluca".

Con el objetivo de construir un modelo de red ambiental de política pública que permita analizar la génesis y desarrollo de individuos y colectivos como una iniciativa que impulse la práctica del turismo en el Parque Nacional "Nevado de Toluca", se retomó la metodología de redes de política pública basada en el contexto natural, político-administrativo, socioeconómico y cultural propuesto por Cruz (2008), considerando las siguientes características: diversidad de actores y metas, distribución de objetivos entre los actores, “cerrazón”, distribución de la información en la red, interdependencia, complementariedad, intensidad de interacción y distribución de poder entre actores en la red. 
Respecto de la obtención de información de campo relacionada con el número de visitantes al Nevado de Toluca, particularmente al Parque de Los Venados; se obtuvo información de fuentes directas, es decir, del Comisariado Ejidal de San Juan de las Huertas, instancia encargada de la administración del Parque mencionado.

\section{Conceptualización y Tipología de las Redes Sociales}

Recientemente el tema de las redes sociales ha cobrado importancia a partir de la cada vez mayor participación de la sociedad en asuntos en los que el gobierno en sus distintos niveles ha desatendido. Particularmente el análisis de las redes, tiene en John Barnes a uno de sus principales exponentes al usar por primera vez el concepto de forma sistemática y analítica (Requena, 1989). En este apartado, se presentan las principales conceptualizaciones de redes sociales, redes de política pública, así como la tipología de las redes sociales.

\subsection{Conceptualización}

Cardozo (2009), establece que la teoría de redes se remonta a los años 30 del siglo XX y hasta su configuración actual, se ha alimentado de conceptos e investigaciones provenientes básicamente de la antropología a partir de los trabajos de Radcliffe-Brown, Barnes y Nadel (1954-1957); de la sociometría de Levy Moreno (1934); de la matemática con la teoría de grafos de Frank Haray (1963); así como de las aportaciones del International Network for Social Network Analysis, INSN, a finales de la década de los años 80. Uno de los primeros en definir la red como un campo social fue Barnes, al considerar a la red como:

\footnotetext{
"un conjunto de puntos algunos de los cuales están unidos por líneas; los puntos son personas o a veces grupos, y las líneas indican qué individuos interactúan mutuamente; así, el conjunto de la vida social genera una red de este tipo". (citado en Adler, 2001: 71 y Requena, 1989: 138).
}

Para Rivoir (1999), una de las principales conclusiones del estudio de Barnes, es que entre la sociedad tradicional y la moderna hay diferencias en la malla de la red. En el caso de la primera, la red es más densa dado que hay más relaciones entre parientes, amigos, y otros miembros de la comunidad; mientras que en la segunda, los agujeros en la red son mayores ya que los vínculos de relación no son tan estrechos; considera asimismo, que en algunos 
estudios sobre redes sociales se percibe un esfuerzo por abandonar el análisis reduccionista e incorporar elementos y dimensiones que permitan un análisis complejo.

Hay casos en los que las redes sociales son utilizadas figurativamente en forma metafórica para expresar cierto tipo de relaciones sin más pretensiones teóricas (Wellman, 1988). En otros estudios se trata de una metodología de carácter empírico con una fuerte base en cuanto a las herramientas estadísticas y fundamentación teórica, en cuyo sentido moderno y genérico se refieren a las relaciones, interconexiones y dependencias personales y sociales (Parsons, 2007). También están aquellos en los que el análisis de las redes sociales se aborda dentro de la investigación social aplicada como objeto/sujeto de la investigación en construcción y a construir desde una metodología de investigación-acción (Rodríguez Villasante, 1994 y 2006); como un enfoque de redes sociales informales a través del cual se considera que son la forma natural de organización de los seres humanos y que en momentos de crisis social cobran más trascendencia y canalizan lo que no es viable de hacer por los canales formales (Motta, 1995); y, finalmente se encuentran ejemplos en donde las redes sociales se consideran como una perspectiva centrada en el intercambio, lo que constituye la esencia de la configuración de las mismas, y que como recurso de afrontamiento, promueve resultados adaptativos, una mejor calidad de vida y en general de bienestar (Muñoz, 2012).

Por su parte, Porras (2012), advierte que las redes sociales tienen dos características importantes: la primera es que son interorganizacionales, pues son el resultado de la convergencia de actores, instituciones, recursos y/o racionalidades de al menos dos sectores (por ejemplo el gubernamental y los mercados; o el gubernamental y el de la sociedad organizada); mientras que la segunda es que poseen cierto grado de autonomía, pues en la práctica compiten con otras redes similares por la asignación de recursos. En este proceso, terminan por privilegiar los intereses de la red por encima de las directrices jerárquicas, por lo que son capaces de resistir el control del nivel administrativo superior.

Un término central para este estudio por lo que implica el enfoque de redes, es el de política pública. Al respecto, Nateras (2006), señala que la definición de política pública se puede entender como una política gubernamental o de alguna organización de la sociedad civil (OSC), en una jurisdicción política, cuando cumple con ciertas características. En términos generales, la política pública es producto de una actividad gubernamental que está integrada 
por un elemento institucional, en virtud de que las decisiones son tomadas por una autoridad formal legalmente constituida, dentro de un sistema político y que estas decisiones se toman considerando la relación fines/medios; lo cual lleva a la acción o la inacción. Además de ello, el consenso y el conflicto son elementos inherentes de la política, por consiguiente, las políticas son elaboradas a partir de la interacción entre el gobierno y los ciudadanos.

Para Bazúa y Valenti (1993), el término policy (política pública), implica toda decisión social, en donde el sujeto de la decisión puede ser un individuo, una organización o el Estado; mientras que para Laswell (citado en Nateras, 2006), son concebidas con una orientación multidisciplinaria, pues por naturaleza conllevan aspectos políticos, económicos, administrativos, culturales, entre otros. Por tanto, y como lo sintetiza Nateras, en la definición de la política pública y dada la participación de distintos actores con poder e intereses diferenciados, habrá que considerar las políticas públicas no solo como conceptos, sino más bien como variables que se pueden aplicar en una diversidad de casos o situaciones de acuerdo con la dimensión en que se analice.

En este sentido, las redes sociales de política pública son una forma de organización donde se establecen y promueven las relaciones horizontales, y en las cuales el sentido de la gobernanza como interacción sociedad-estado para la toma de decisiones, permite establecer un enfoque que tiene que ver con la propia identificación de las redes, la articulación públicoprivada y la convergencia entre actores (Porras, 2012).

Particularmente, la construcción de un modelo metodológico para el análisis de redes sociales de política pública (RSPP), basado en el contexto natural, político-administrativo, socioeconómico y cultural (Cruz, 2008), contempla las características indicadas en la tabla 1. Es importante mencionar que en el trabajo de Cruz (2008), se hace alusión a las características de las redes de política pública, la combinación de las mismas implica que las redes están cambiando constantemente, ya que la modificación de una de esas características influye en el comportamiento de otra; como resultado de ello, las redes casi siempre son altamente dinámicas y por lo tanto en éstas pueden ocurrir eventos impredecibles, aspectos que son congruentes al análisis de la complejidad que se plantea en esta investigación. 
Tabla 1. Características de las Redes Sociales de Política Pública

\begin{tabular}{|c|c|}
\hline $\begin{array}{c}\text { Características de } \\
\text { las RSPP }\end{array}$ & Descripción \\
\hline $\begin{array}{l}\text { 1. Diversidad de } \\
\text { actores y metas: }\end{array}$ & $\begin{array}{l}\text { Las redes de política pública constan de una gran variedad de actores con } \\
\text { metas y estrategias propias. Una política es el resultado de la interacción } \\
\text { entre una gran variedad de actores. }\end{array}$ \\
\hline $\begin{array}{l}\text { 2. Distribución de } \\
\text { objetivos entre los } \\
\text { actores: }\end{array}$ & $\begin{array}{l}\text { Los objetivos pueden ser compatibles o no. No lo son cuando la } \\
\text { realización del objetivo de un actor impide la realización del objetivo de } \\
\text { otro. La cohesión en la red es una extensión en la cual los actores } \\
\text { simpatizan con los objetivos de unos y otros, lo que generalmente se } \\
\text { produce por los valores y visión de la realidad compartidas. }\end{array}$ \\
\hline 3. “Cerrazón”: & $\begin{array}{l}\text { Ocurre cuando ciertos actores son excluidos de la interacción, ya sea } \\
\text { porque otros integrantes en la red fallaron en apreciar su contribución o no } \\
\text { la consideraron relevante. }\end{array}$ \\
\hline $\begin{array}{l}\text { 4. Distribución de la } \\
\text { información en la } \\
\text { red: }\end{array}$ & $\begin{array}{l}\text { La igualdad (o falta de igualdad) en términos de cantidad, calidad y } \\
\text { percepción de información disponible para los actores individuales es } \\
\text { importante. Dicha falta de igualdad supondría desventajas para los } \\
\text { participantes que no tienen igual acceso a la información. }\end{array}$ \\
\hline 5. Interdependencia: & $\begin{array}{l}\text { La interdependencia entre actores puede ser expresada por diversas } \\
\text { variables (financiera, apoyo económico, espacio, etcétera) y ser simple o } \\
\text { muy compleja. En varios momentos los actores se darán cuenta de que son } \\
\text { dependientes de otro. Un personaje aislado de su ambiente o de otro actor } \\
\text { es difícil de influir, mientras que cada actor intentará usar esas } \\
\text { interdependencias para su propio beneficio. }\end{array}$ \\
\hline $\begin{array}{l}\text { 6. Complementarieda } \\
\text { d: }\end{array}$ & $\begin{array}{l}\text { Consiste en que las redes se mantienen y benefician de la diversidad de sus } \\
\text { componentes. La interdependencia es la cooperación en la red, basada en } \\
\text { la premisa de que ninguno de los grupos participantes puede dirigir la } \\
\text { temática por sí mismo, lo que da como resultado la creación de puentes } \\
\text { entre participantes de diversos sectores, lo cual refleja roles cambiantes y } \\
\text { el poder entre esos grupos. }\end{array}$ \\
\hline $\begin{array}{l}\text { 7. Intensidad } \\
\text { interacción: }\end{array}$ & $\begin{array}{l}\text { Uno de los factores que influye en la interacción, es cómo están } \\
\text { distribuidos entre los actores sus objetivos, fuentes de poder e información. } \\
\text { La interacción no sólo se refiere a los contactos durante la formación de la } \\
\text { política; también a sus relaciones fuera de dicha fase, porque es posible } \\
\text { que se encuentren unos a otros en otras etapas de la política pública. Esta } \\
\text { intensidad de interacción entre ellos son las "interconexiones", que pueden } \\
\text { ser fuertes o débiles. }\end{array}$ \\
\hline 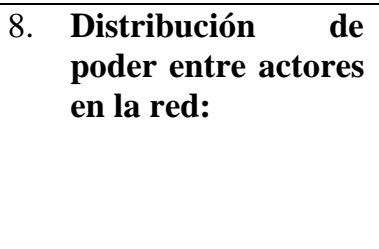 & $\begin{array}{l}\text { Debería existir un perfecto balance de poder o, un actor podría dominar a } \\
\text { los otros, resultado de que supere a los otros en cuanto a interacciones } \\
\text { fuertes y positivas, objetivos compatibles y mayor acceso a la información, } \\
\text { entre otros aspectos inherentes al juego político. El poder está ligado con } \\
\text { la posesión de recursos o con la asimetría de relaciones de dependencia } \\
\text { entre actores. }\end{array}$ \\
\hline
\end{tabular}

Fuente: Cruz (2008: 65) 


\subsection{Tipología}

Diversos autores han establecido una tipología de las redes sociales que ha permitido contar con un marco a partir del cual se ubican modelos, estructuras o formas específicas para el análisis y explicación del tejido social. A continuación se muestran los más representativos.

Para Adler (2001), las relaciones entre miembros de una red son esencialmente relaciones de igualdad social. Por ello, el intercambio adquiere la forma de reciprocidad, siempre sobre una base estrictamente igualitaria; en este sentido, los objetos de intercambio en las redes se consideran como una parte esencial de su origen. Algunas tipificaciones de las redes sociales que tienen como referencia los tipos de intercambio y las interconexiones entre los miembros, implican tres tipos de redes: a) redes basadas en la reciprocidad, en las cuales se produce un intercambio entre pares de bienes y servicios como parte integral de una relación social duradera; b) redes basadas en la redistribución de bienes y servicios, que se centran primero en un individuo o institución para luego distribuirse en la comunidad o sociedad; y c) redes basadas en el mercado, en las que los bienes y servicios se intercambian sobre la base de la ley de oferta y demanda, sin implicaciones sociales de largo plazo. Polanyi (citado en Guzmán et. al., 2003), destaca el reciente predominio del intercambio de mercado por sobre las otras formas. Sin embargo, agrega que en ningún sistema social se excluye alguno de estos tipos de intercambio, sino que más bien coexisten unos con otros.

En términos de interconexiones entre los miembros, Guzmán et al., (2003), indican que, según el grado de interconexión, pueden identificarse al menos dos tipos de redes que, en la práctica, suelen ser complementarios: a) redes basadas en contactos personales, esta red también es conocida como red egocéntrica, debido a que se basa en las relaciones personales de cada individuo, favoreciendo las relaciones diádicas, es decir, aquellas que se dan entre dos elementos de la red y que van condicionadas por el conjunto de la misma (Garrido, 2001); y, b) redes basadas en contactos grupales, en las que la persona se relaciona con miembros de grupos estructurados en torno de agrupaciones y organizaciones de las cuales forma parte. Este tipo de red favorece las relaciones poli diádicas, (líneas, vínculos, lazos), y se basa en el intercambio entre todos los participantes de la red.

En cuanto a sus componentes, Guzmán et al., (2003), establecen que las redes pueden ser de dos tipos: de apoyo personal y comunitarias. Las primeras son familiares y no familiares; 
mientras que las segundas incluyen organizaciones a nivel comunitario: no públicas con actividades propias (privadas, organizaciones no gubernamentales ONG's, voluntariado, religiosa, otras); instituciones públicas o adscritas al sector público a nivel comunitario; y, organizaciones e instituciones públicas de gran alcance, vinculadas a políticas nacionales.

Para Cardozo (2009), la tipología de las redes sociales consiste en tres rubros: a) centralizada, en donde los nodos se conectan a través de un único nodo que concentra y distribuye la información; b) descentralizada, la cual es una réplica de la estructura anterior en varias redes centralizadas. La diferencia con la red centralizada es que la información no se concentra ya en un solo actor. Un problema que las afecta es que cuando se cae un nodo los que se conectan a la red a través de él quedan incomunicados; y c) distribuida: en la cual cualquier nodo se conecta con cualquier otro, diseminando la información de forma más eficiente y logrando que la desaparición de un nodo no afecte de forma irrevocable la estructura de la red.

De esta manera, y considerando que hay una ausencia de referencias sobre la conceptualización de redes ambientales, es importante en primera instancia, definir lo que es una red ambiental y posteriormente establecer un referente con base en la tipificación que permita darle sentido al trabajo que realizan. En esta investigación se considera como red ambiental o ambientalista a los grupos de la sociedad civil organizada, así como de individuos de reconocido prestigio académico y empresarial, que a partir de una iniciativa de consenso, establecen una serie de compromisos en pro del ambiente. Una particularidad relevante, es que este tipo de redes responden básicamente a dos líneas fundamentales: la primera, referida a la cooperación incondicional entre los miembros (reciprocidad); y la segunda, a la generación de pronunciamientos -es decir, de elementos que posteriormente se transformen en políticas públicas. Así, y considerando los aspectos mencionados, las redes ambientales se clasificarían entonces como redes de contactos grupales o comunitarias (con base en sus interconexiones), de reciprocidad (por su objetivo) y distribuidas (por su grado de comunicación). 


\section{Redes Ambientales en México}

El papel que el ambientalismo como movimiento multidimensional ha representado desde la década de los años 70, y se puede decir que aún hasta ahora, ha tenido que ver con la crítica a los modos de producción, los estilos de vida y los criterios de generación y aplicación de los conocimientos en el proceso de desarrollo, expresándose así, en un asunto contradictorio de participación-marginación, apertura-represión, concertación-mediatización, emergiendo como portadores de una cultura democrática, aportando nuevos valores, perspectivas, métodos y acercamientos a la arena política (Aranda, 2002).

Torres (1998), señala que además de que no existe un consenso sobre la definición de las organizaciones no gubernamentales (ONG's), dentro de las cuales se identifican los grupos ambientales, se les tiende a ubicar en el rubro de aquellas que persiguen objetivos públicos fuera del aparato formal del Estado y que además son voluntarias, no persiguen fines de lucro y dependen de donaciones para desarrollar su labor. Sin embargo, los atributos de altruismo y voluntarismo ya no pueden considerarse como características definitorias de las ONG's, al igual que su independencia total del Estado; incluso, Torres (1998), considera asimismo que las presiones en cuanto a la génesis de algunas ONG's pueden venir desde abajo, cuando por ejemplo, la voluntad de los actores se da en relación a ciertos problemas públicos; o de presiones desde arriba, en el momento en que los deseos de los gobiernos se dan para descentralizar ciertas acciones ante la quiebra del Estado Benefactor.

Por su parte, Ávila (1998), considera que particularmente en México desde el sexenio salinista, la participación social en la política ambiental se resaltó su importancia a través de estrategias de consenso, corresponsabilidad e iniciativas comunitarias, tendencia que la Secretaría de Medio Ambiente y Recursos Naturales (SEMARNAT), ha continuado mediante la instauración de consejos consultivos y técnicos. Por lo que en las últimas décadas, el número de organizaciones ambientalistas se ha multiplicado, presentando preponderantemente las siguientes características:

a) Su creación data de los años ochenta;

b) Su figura jurídica tiende a ser la de asociación civil;

c) Procuran el autofinanciamiento, principalmente a través de asesorías; 
d) Menos de la tercera parte está integrada en redes; y,

e) Sus líneas de acción se centran en temas como el agua, educación ambiental, energía, reforestación, tecnología apropiada, flora y fauna y agricultura orgánica, dejando como aspecto secundario a la basura, investigación, turismo, aire, pesca, salud, biodiversidad y planificación urbano-rural.

Actualmente la dirección que han tomado algunos grupos ambientales tiene que ver con cierta "dependencia" respecto del apoyo que el Estado les otorga fundamentalmente en materia económica, lo cual desde la perspectiva de Morales y Sojo (1998), es una relación que pese a tener avances reales, presenta dificultades significativas; algunas de ellas se manifiestan en discrepancias sobre la concertación, el grado de representatividad de las partes, la visión sobre la política de desarrollo sostenible y en general sobre los temas de la agenda ambiental; incluso los autores afirman que el gobierno las ve únicamente como técnicos de apoyo para ciertas acciones o prestadores de servicios en áreas donde el mismo no cumple su función.

Particularmente en el Estado de México en el transcurso del segundo semestre de 2010, se creó la primera Red de Ambientalistas (REDAEM), cuya iniciativa tuvo como base tres aspectos fundamentales: a) conocerse, estar al tanto de las actividades de cada grupo o persona, tener la posibilidad de contactarse; b) hacer sinergia, brindarse apoyo y experiencia para conjuntar actividades; y, c) ser un grupo de presión, es decir procurar el activismo ambiental, de tal manera que mediante pronunciamientos, se asuma una postura frente a los problemas ambientales. Con base en lo anterior, la REDAEM establece líneas de acción para organizar los esfuerzos de los grupos ambientales, gestionar recursos, aprovechar la fortaleza de la voz colectiva de los miembros; y difundir noticias sobre las actividades de los integrantes y en general de quienes generan acciones ambientales (Mejía Alonso, 2012).

La Red tuvo su primera reunión el 24 de julio de 2010 y a partir de entonces se consideró que no debería haber un presidente de la Red y por eso se propuso que se creara un secretariado conformado por representantes de cuatro asociaciones. Como colectivo, la REDAEM tiene en su haber seis reuniones en las cuales han participado 51 grupos y 18 personas independientes, cuya formación y desarrollo abarcan ámbitos como el educativo, religioso-espiritual, empresarial, medios de comunicación, grupos dedicados a la promoción de actividades locales de educación ambiental, así como individuos provenientes de instituciones académicas los 
cuales se han integrado debido a su capacidad de gestión y aportación en el ámbito ambiental. Para consolidar la Red, recientemente y en el marco del convenio de colaboración con la Comisión de Derechos Humanos del Estado de México, se otorgaron los nombramientos a cada uno de los integrantes de la misma, lo cual sienta un precedente para el movimiento ambientalista de la entidad.

La experiencia de la REDAEM en términos de generación de pronunciamientos es todavía incipiente; sin embargo, algunos de sus integrantes han participado en grupos de trabajo para impulsar acciones encaminadas a la implementación de estrategias como el uso de bicicletas en zonas urbanas, el desarrollo de proyectos ecoturísticos en la zona oriente del Estado de México, y de conservación de Áreas Naturales Protegidas, particularmente en el Parque Nacional "Nevado de Toluca", en donde se han involucrado en prácticas para la recuperación y conservación de áreas erosionadas afectadas por la constante deforestación, por actividades recreativas como el uso de motocicletas y cuatrimotos; y por el desarrollo de labores agrícolas y de pastoreo. Asimismo, es de resaltar su desempeño en la limpieza de cuerpos de agua (lagunas en el cráter), ríos y arroyos, reforestación de áreas deterioradas, así como la introducción de modelos de producción orgánica (Cruz, 1997; De la Rosa, 2010; Mandujano, 2011 y Hernández García 2012).

Es importante destacar que derivado de los apuntes de Ávila (1998), sobre el hecho de que menos de la tercera parte de las ONG's ambientalistas está integrada a una red; así como del papel secundario que juega el turismo en las prioridades de individuos y colectivos ambientalistas; la REDAEM está sentando las bases para agrupar a los ambientalistas de la entidad, de tal manera que se busca potencializar sus capacidades en el entendido de que como red ambiental de políticas públicas y en un momento de coyuntura en cuanto a la participación de la sociedad civil a nivel nacional, incida en la solución de problemas ambientales y particularmente en el desarrollo de la actividad turística en la entidad.

\subsection{Nuevas alternativas, nuevos caminos para el turismo: las redes ambientales de políticas públicas}

A la luz del pensamiento de García (2006), los problemas ambientales locales, regionales y globales, son problemas complejos (Sánchez Barreto, 2012), de tal manera que la solución a estas realidades no podría plantearse desde una perspectiva disciplinaria o simplemente desde 
la visión de un solo investigador. Partiendo entonces de que el abordaje de un problema ambiental se establece como el eje de acción de una red, para este caso de una red ambiental; este trabajo tiene entre uno de sus propósitos, acercar dicho eje al objeto de estudio local llamado turismo.

Habrá que señalar que el turismo ha sido analizado como un fenómeno social (De la Torre, 1980), como una industria (Rodríguez Woog, et al., 1986), e incluso como objeto de estudio científico (Jafari, 2005); posturas que han permitido considerarlo como una actividad relevante en el ámbito económico, social y ambiental. Sin embargo, en la vida diaria y como lo señala Espinosa (2007), el establecimiento de actividades turísticas en cualquier lugar implica la aparición de problemáticas ambientales y la disposición de desechos sólidos, la transculturación en las comunidades donde llega el turismo, así como fenómenos delictivos o de tipo sexual, entre otras repercusiones como la aparición de nuevos mecanismos de aprovechamiento y explotación de los recursos naturales precisamente en áreas naturales protegidas, la inseguridad social y la crisis económica, lo cual evidencia la falta de congruencia entre la visión del turismo conceptualizado por la Organización Mundial del Turismo (OMT), con la perspectiva de la política turística nacional, estatal e incluso municipal.

Considerando las directrices de la OMT (1999: 11-15), y del Programa de Turismo Sustentable en México (SECTUR, 2012), sobre las tendencias turísticas de sustentabilidad, se requiere impulsar

la utilización de sistemas tradicionales de climatización (basados en recursos del entorno), la recogida selectiva de desechos, las políticas de concienciación sobre la necesidad de ahorro en el consumo de recursos básicos (agua, suelos, madera), o la utilización de energías renovables (solar, eólica, marina o biológica), son algunos ejemplos de iniciativas relativamente simples que conectan claramente con las nuevas dinámicas observadas en el sector. Lo anterior de ha de complementar con la modernización de estructuras organizativas así como del marco institucional que contemple al turismo como política prioritaria en un contexto donde prevalezca la convicción de que la comunidad local y el municipio deben de tener un papel más activo, menos subsidiario y pasivo en las decisiones turísticas; en donde a través de una nueva planificación local, se establezcan criterios al mismo nivel de intervención entre agentes económicos y sociales del turismo con la participación de la comunidad local; teniendo a la 
sostenibilidad ambiental, social y económica como hilo conductor de la política turística local” (OMT, 1999, pgs: 11-15).

Dichas tendencias implican como lo establece el Programa de Turismo Sustentable en México (SECTUR, 2012), promover viajes con menor impacto ambiental; elegir el destino tomando en cuenta el nivel de conservación del entorno natural; intensificar el interés en temas sociales, culturales y ambientales de los destinos turísticos; justificar y costear la conservación de áreas naturales, de la vida silvestre, de sitios arqueológicos e históricos; mejorar la calidad global ambiental; fortalecer la conciencia ambiental de los residentes; generar empleos directos e indirectos; contribuir a conservar el patrimonio cultural (danza, música, artesanía, vestimenta tradicional, costumbres, tradiciones); fomentar un orgullo renovado de los residentes por su cultura y por su tierra; propiciar el intercambio cultural entre turistas y residentes, el buen entendimiento, la aceptación, así como las relaciones pacíficas; evitar la especulación de la tierra (recursos naturales), así como promover un enfoque integral de participación social en el diseño, implementación y evaluación de políticas turísticas que fortalezca el desarrollo local, regional y global de la actividad.

Específicamente, las Áreas Naturales Protegidas (ANP), son espacios que requieren contar con nuevas iniciativas para el desarrollo de un turismo que logre armonizar las necesidades de las comunidades locales con las políticas institucionales, los intereses de los empresarios, el liderazgo de la sociedad civil organizada y las demandas de los visitantes, de tal suerte que el esquema de turismo resultante, sea más congruente con la dinámica de la vida social actual, es decir, encaminada a una vida saludable, a contar con espacios cada vez más verdes, a la práctica de la no-violencia, la responsabilidad social y el consumo responsable. Entre dichas iniciativas, se encuentran precisamente la estructuración de Redes Ambientales de Políticas Públicas (RAPP), que impulsen mecanismos de relaciones entre el turismo y otros aspectos que necesariamente lo vinculen a lo armónico: la espiritualidad, los valores, la seguridad, el comercio justo, la cultura de la prevención y protección civil, la gestión ambiental (manejo integral de residuos, agua, suelo, aire, ruido, luminosidad, agentes perturbadores), la atención a comunidades vulnerables, la salud, entre otros, que semejando una orquesta, concierten una actividad que hasta ahora, ha sido considerada fundamentalmente desde el punto de vista económico. 


\section{Turismo en el Parque Nacional "Nevado de Toluca"}

El turismo, es una actividad que se ha realizado en el "Nevado de Toluca" sin un programa y control alguno, provocando en muchos de los casos contaminación por ruido, "basura", extracción de flora y práctica de caza. Actualmente no existe una red que fomente las interacciones entre actores en el área natural, no obstante la presencia de grupos ambientales que de manera aislada desarrollan programas de conservación de especies de fauna y producción de hortalizas y frutos del bosque de manera orgánica en espacios focalizados.

En la propuesta de recategorización del "Nevado de Toluca" que actualmente promueve el gobierno de la entidad, es decir, pasar de la categoría de Parque Nacional a Área de Protección de Flora y Fauna "Nevado de Toluca" (APFF-NT); dos de los principales atractivos turísticos del Parque, los lagos cráter y el Parque de Los Venados, son considerados como parte de la zona núcleo, cuya superficie rebasa las 1900 hectáreas. En dicha propuesta, también se considera una zona de amortiguamiento, como puede observarse en el mapa 2, la cual ha sido definida como área para el "aprovechamiento", sin definirse aún concretamente las actividades que podrán impulsarse.

Es importante mencionar que con base en el Programa de Conservación y Manejo del Parque Nacional "Nevado de Toluca" (CONANP, 2008), el Parque de los Venados (PV), y área circundante, (Comunidad de Raíces, Lagos y Cráter), se considera como una subzona de uso público ubicada entre los $99^{\circ} 47^{\prime} 24^{\prime}$ ' longitud oeste y $19^{\circ} 7^{\prime} 48^{\prime}$ ' latitud norte, a una altitud de $3600 \mathrm{msnm}$, teniendo como su principal vía de acceso un camino de terracería. La tenencia de la tierra es ejidal y se caracteriza por un uso de suelo silvícola (preponderantemente de bosque de pino, pinus hartwegii, aunque también existen pequeños fragmentos aislados conformados por comunidades de pinus montezumae), así como reservorio de ardillas, conejos, armadillos y aves silvestres. 


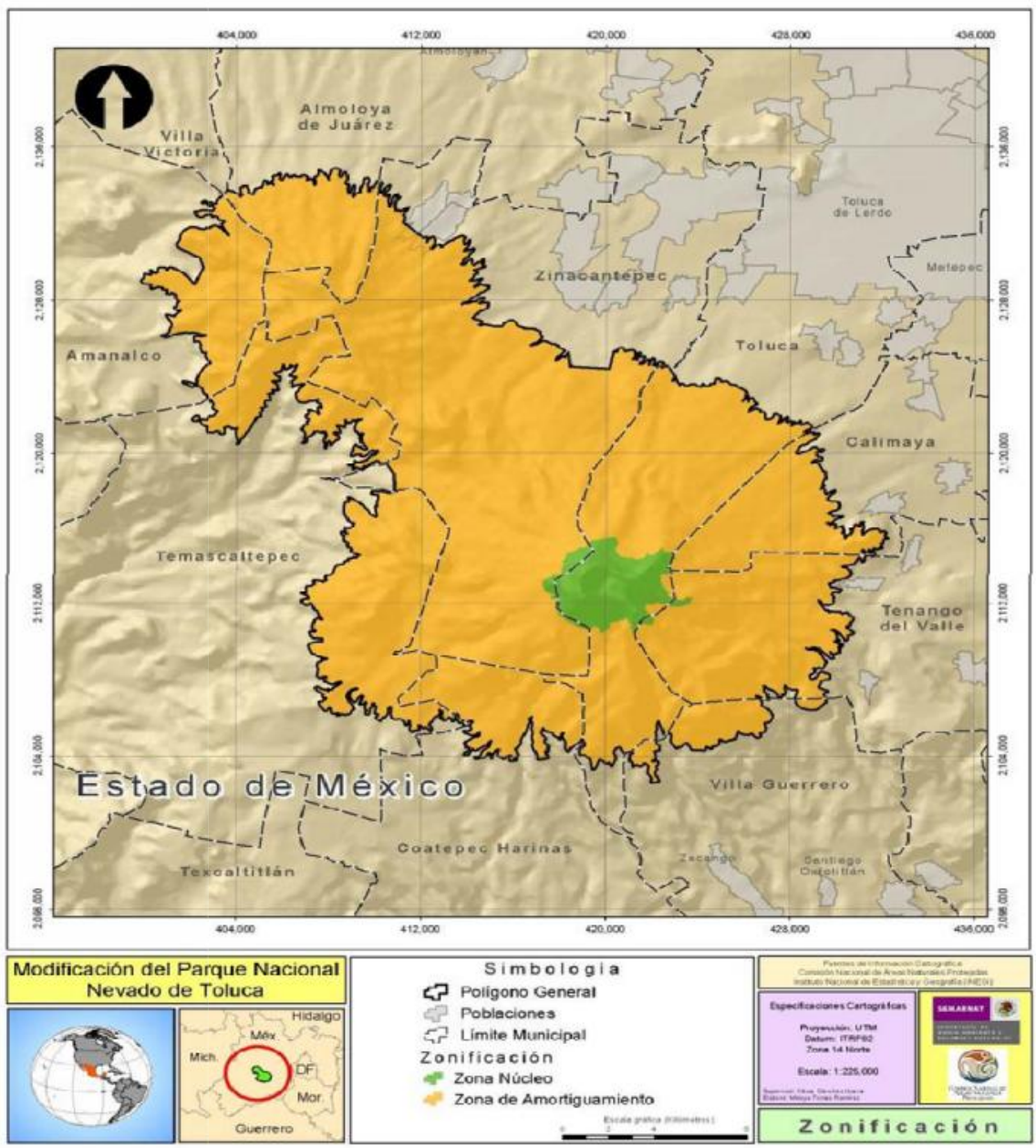

Mapa 2. Zonificación propuesta para el APFF-NT

Fuente: CONANP 2013

Como parte de las acciones para fomentar el turismo, recientemente se construyó en el PV un conjunto de palapas para dar un mejor servicio a los visitantes; sin embargo, también se edificaron locales comerciales que a primera vista rompen con el paisaje. La caseta de entrada al mismo está en malas condiciones, tanto como los juegos infantiles y en general la señalización, servicios (alimentos) e infraestructura (sanitarios, áreas para estacionamiento, senderos para caminatas, así como para bicicletas).

El Parque Nacional "Nevado de Toluca", ha sido un referente para el turismo en el Estado de México; sin embargo, la falta de planeación de actividades turístico-recreativas de bajo 
impacto como la implementación de senderos para caminatas, el uso de transporte no contaminante, la introducción de Unidades de Manejo Ambiental para la reproducción y conservación de fauna como el venado cola blanca y el conejo teporingo, especie esta última endémica del centro de México, así como la consideración de mecanismos para el impulso de alternativas basadas en el ecoturismo, turismo rural y turismo arqueoastronómico (con el apoyo de la Asociación Astronómica del Valle de Toluca); han generado tal y como lo comenta el Presidente del Comisariado Ejidal, que en el PV se reciban aproximadamente 500 vehículos al mes, con la afluencia de alrededor de 2 mil visitantes en temporada baja, incrementándose esa cifra en temporada alta (vacaciones), específicamente en los meses de enero y febrero, cuando se presentan nevadas, tiempo en el cual solamente en un día y en un espacio reducido como lo es la comunidad de Raíces, se llegan a tener hasta 5 mil visitantes; de ahí que el uso del suelo en esta área sea intensivo, requiriendo por lo tanto de iniciativas de participación social como las redes ambientales, en donde se logren conjuntar intereses, esfuerzos, voluntades, recursos y conocimientos, entre las comunidades locales y los actores políticos, académicos, sociales y empresariales.

\section{Modelo de Análisis de una Red Ambiental de Políticas Públicas para el Desarrollo del Turismo en el Parque Nacional "Nevado de Toluca"}

La actividad turística en el marco de una realidad compleja, aprovecha los recursos naturales y culturales como atractivos para su población objetivo; en ese sentido, se requiere establecer un modelo de análisis que permita vincular los componentes del sistema complejo y de redes para impulsar como se señaló en el apartado anterior, acciones armónicas en el Parque Nacional "Nevado de Toluca". En la figura 1 se ejemplifica el enfoque de sistemas complejos y redes ambientales de políticas públicas. 


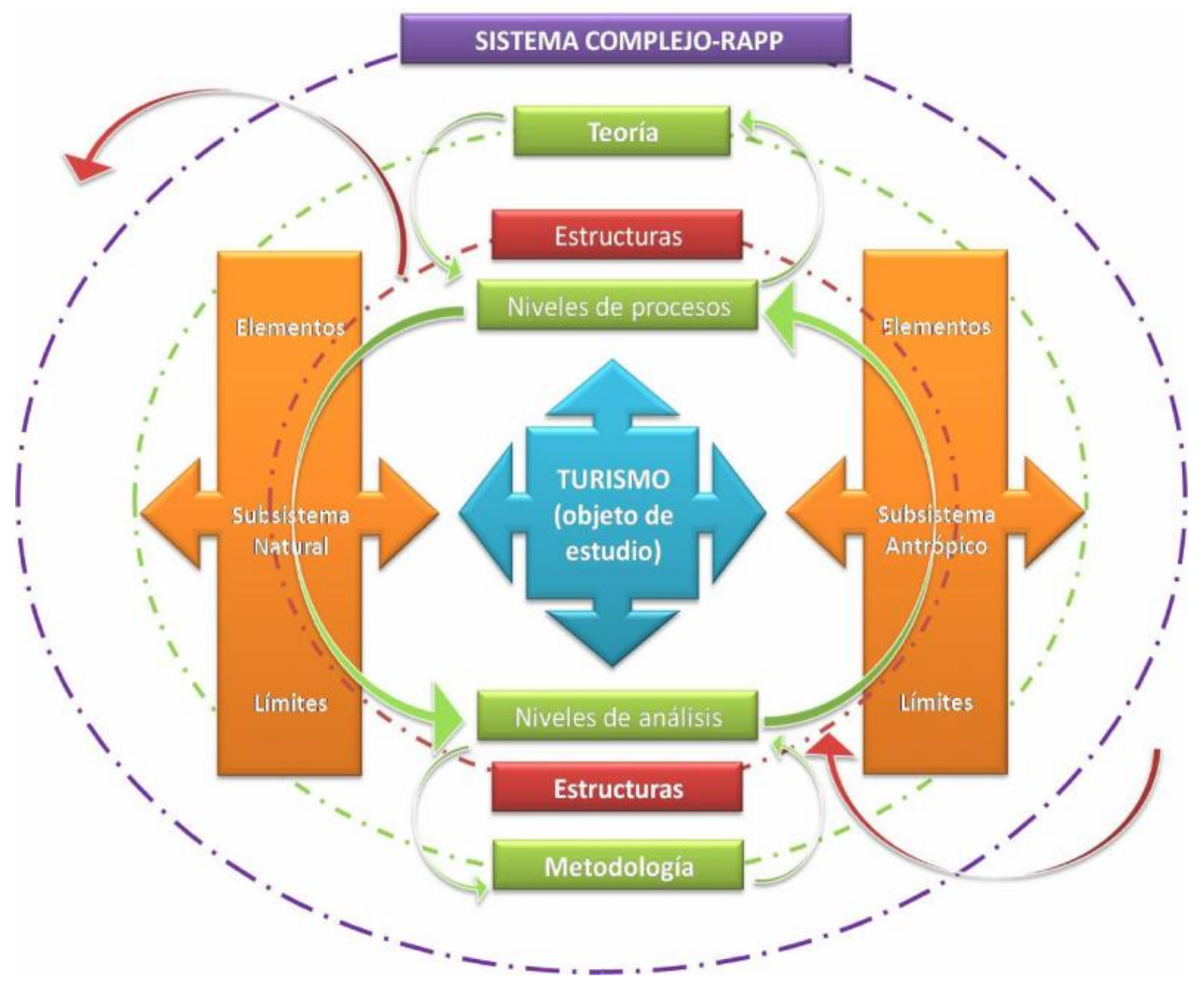

Figura 1. Sistema Complejo-RAPP

Fuente: elaboración propia

En esta figura, el sistema complejo-rapp, parte inicialmente del concepto de sistema desde la perspectiva de García (2000), quien establece que no es solo un conjunto de elementos, sino un conjunto de relaciones entre ciertos elementos que pueden vincularse entre sí con referencia al funcionamiento del conjunto como totalidad. Tomando como base al turismo como objeto de estudio, las estructuras se manifiestan interna y externamente, lo cual se traduce en relaciones dentro y fuera de los límites del sistema complejo. Habrá que hacer hincapié en que dichas relaciones pueden afectar positiva o negativamente a la estructura del sistema, lo cual se expresa en la dinámica del mismo.

Concretamente y para nuestro caso, dichas relaciones implican el vínculo de las redes ambientales hacia el interior del sistema, tanto como el nexo con otros sistemas, de tal manera 
que por ejemplo, el proceso de diseño base de pronunciamientos desde el interior de la red, presupone los fundamentos de construcción de una política pública hacia el exterior.

Tabla 2. Esquematización del Sistema Complejo-RAPP

\begin{tabular}{|c|c|c|c|c|}
\hline $\begin{array}{c}\text { Sistema } \\
\text { Complejo - } \\
\text { RAPP }\end{array}$ & Teoría & Metodología & Componentes & Turismo \\
\hline \multirow{6}{*}{$\begin{array}{l}\text { Enfoque } \\
\text { teórico- } \\
\text { metodológico } \\
\text { para el análisis } \\
\text { de redes } \\
\text { ambientales y } \\
\text { políticas } \\
\text { públicas con } \\
\text { énfasis en el } \\
\text { desarrollo de } \\
\text { la actividad } \\
\text { turística en } \\
\text { áreas } \\
\text { naturales. }\end{array}$} & \multirow{6}{*}{$\begin{array}{l}\text { Sistemas } \\
\text { Complejos: } \\
\text { - Epistemología } \\
\text { Genética } \\
\text { - Constructivismo }\end{array}$} & \multirow{6}{*}{$\begin{array}{l}\text { Sistemas } \\
\text { Complejos/ } \\
\text { Redes de } \\
\text { Política Pública: } \\
\text { - Recorte de la } \\
\text { realidad } \\
\text { analizable como } \\
\text { una totalidad } \\
\text { organizada } \\
\text { - Enfoque de } \\
\text { redes de } \\
\text { política pública }\end{array}$} & $\begin{array}{l}\text { Elementos (las unidades son } \\
\text { complejas): } \\
\text { - Subsistema natural: } \\
\text { - Subsistema antrópico: }\end{array}$ & $\begin{array}{l}\text { - Parque Nacional } \\
\text { Nevado de Toluca. } \\
\text { - Comunidad local. }\end{array}$ \\
\hline & & & $\begin{array}{l}\text { Límites (El sistema es } \\
\text { abierto, por lo tanto se } \\
\text { carece de límites precisos) }\end{array}$ & $\begin{array}{l}\text { Parque Nacional } \\
\text { (Parque de los } \\
\text { Venados) }\end{array}$ \\
\hline & & & $\begin{array}{l}\text { Estructuras (Determinadas } \\
\text { por las relaciones entre } \\
\text { elementos) }\end{array}$ & $\begin{array}{l}\text { Red de Ambientalistas } \\
\text { del Estado de México } \\
\text { (REDAEM) y su } \\
\text { relación con los } \\
\text { subsistemas }\end{array}$ \\
\hline & & & $\begin{array}{l}\text { Niveles de análisis } \\
\text { (Interrelacionados): } \\
\text { - Tercer nivel: nacionales o } \\
\text { internacionales. } \\
\text { - Segundo nivel: regionales } \\
\text { o nacionales. } \\
\text { - Primer nivel: locales. }\end{array}$ & $\begin{array}{l}\text { - Deterioro ambiental. } \\
\text { - Modelos turísticos } \\
\text { alternativos. } \\
\text { - Turismo en áreas } \\
\text { naturales. }\end{array}$ \\
\hline & & & $\begin{array}{l}\text { Niveles de procesos } \\
\text { (Determinados): } \\
\text { - Tercer nivel: políticas y } \\
\text { modificaciones nacionales e } \\
\text { internacionales. } \\
\text { - Segundo nivel: cambios en } \\
\text { los sectores productivos } \\
\text { nacionales y regionales. } \\
\text { - Primer nivel: cambios en el } \\
\text { medio físico y en las } \\
\text { comunidades locales }\end{array}$ & $\begin{array}{l}\text { - Política nacional } \\
\text { turística. } \\
\text { - Política estatal y } \\
\text { municipal turística. } \\
\text { - Política de } \\
\text { recategorización del } \\
\text { Parque Nacional. }\end{array}$ \\
\hline & & & $\begin{array}{l}\text { Dinámica del sistema } \\
\text { (perturbaciones endógenas y } \\
\text { exógenas): } \\
\text { - Estado estacionario: } \\
\text { - Desestructuración: } \\
\text { - Reestructuración: }\end{array}$ & $\begin{array}{l}\text { - Estado actual de las } \\
\text { condiciones del Parque } \\
\text { Nacional. } \\
\text { - Cambios debido a } \\
\text { perturbaciones. } \\
\text { - Sistema modificado. }\end{array}$ \\
\hline
\end{tabular}

Fuente: elaboración propia 
Con respecto a los componentes del sistema, estos se entrelazan vía el objeto de estudio. El engranaje de los componentes en este caso tiene que ver con tres aspectos fundamentales: la teoría, la metodología y los componentes del sistema, los cuales dan dinamismo y trascendencia al sistema. El artificio teórico-metodológico, es en palabras de García, (2000: 78), un "laborioso proceso de sucesivas aproximaciones", es decir, un proceso dialéctico que proporciona las herramientas que permiten ubicar a las redes ambientales en un recorte de la realidad que se ve influido por distintos niveles tanto de procesos, como de análisis. En la tabla 2, se esquematizan y desglosan los componentes del sistema complejo-rapp, de tal manera que a partir de ello se fortalece la explicación de la figura 1.

La explicación del modelo (figura 1 y tabla 2), requiere así mismo de la adecuación de la propuesta de Cruz (2008), para la caracterización en este caso de la REDAEM como una red ambiental de políticas públicas (RAPP), lo cual complementa la propuesta general del modelo, como se observa en la tabla 3. Así, la REDAEM cumple con las características establecidas por Cruz para considerarse como una red de política pública.

Este planteamiento en el cual las RAPP se mueven, reflejo de un dinamismo que tiene como un indicador significativo las posiciones de poder de los actores, centradas en las relaciones (estructuras), que han ido construyendo a lo largo de su historia individual o colectiva, resalta el enfoque de sistemas complejos que se propone en la investigación (García, 2006).

Tabla 3. Características de la REDAEM como RAPP

\begin{tabular}{|l|l|}
\hline \multicolumn{1}{|c|}{ Características } & \multicolumn{1}{|c|}{ Descripción } \\
\hline $\begin{array}{l}\text { Diversidad de actores y } \\
\text { metas }\end{array}$ & $\begin{array}{l}\text { Está integrada por una variedad de actores, tanto del sector privado como del social } \\
\text { (51 grupos y } 18 \text { ambientalistas independientes). No existe actor central, la Red está } \\
\text { conformada por un Secretariado de 4 representantes Fundación Xochitla, } \\
\text { Ambientalmex, Fundación Tláloc y Red Acción Ambiente). }\end{array}$ \\
\hline $\begin{array}{l}\text { Distribución de } \\
\text { objetivos entre los } \\
\text { actores }\end{array}$ & $\begin{array}{l}\text { La cohesión de la red está determinada por el objetivo central que es el tema } \\
\text { ambiental, en donde se hacen explícitos tanto los valores como la visión de la } \\
\text { realidad compartida. }\end{array}$ \\
\hline "Cerrazón” & $\begin{array}{l}\text { La inclusión-exclusión de actores, se da en función del contacto que se tiene sobre } \\
\text { todo con integrantes del Secretariado (dicho contacto se da inicialmente de forma } \\
\text { presencial; sin embargo, los medios electrónicos son la herramienta que permite } \\
\text { mantener en funcionamiento la red), la asistencia a los foros o eventos convocados y } \\
\text { en general a la disposición hacia el trabajo compartido. }\end{array}$ \\
\hline
\end{tabular}




\begin{tabular}{|l|l|}
\hline $\begin{array}{l}\text { Distribución de la } \\
\text { información en la red }\end{array}$ & $\begin{array}{l}\text { Aplica en el hecho de que el Secretariado cumple con una mejor posición dentro de la } \\
\text { Red porque precisamente tienen la capacidad de activar a otros, se han movilizado } \\
\text { para la obtención de recursos, así como han ocupado puestos de relevancia en el } \\
\text { sector ambiental. }\end{array}$ \\
\hline Interdependencia & $\begin{array}{l}\text { Las relaciones dentro de la Red se han dado en función de la "amistad" para invitar a } \\
\text { otros a formar parte de la misma. Existen ambientalistas independientes cuya } \\
\text { fortaleza radica no precisamente en la actividad colectiva, sino en los logros } \\
\text { personales, lo cual en un momento dado pudiera hacerlos más dependientes de los } \\
\text { grupos; situación que en algunos casos más bien se da al revés. }\end{array}$ \\
\hline Complementariedad & $\begin{array}{l}\text { Las experiencias, conocimientos, así como el interés específico de los integrantes de } \\
\text { la Red por dar solución a ciertos problemas, permiten establecer una } \\
\text { complementariedad que se traduce en "pronunciamientos", los cuales se refieren a los } \\
\text { antecedentes que con base en procedimientos formales, pueden transformarse } \\
\text { posteriormente en una política pública. }\end{array}$ \\
\hline $\begin{array}{l}\text { Intensidad de } \\
\text { interacción }\end{array}$ & $\begin{array}{l}\text { Un aspecto fundamental en la interconexión entre los actores para la formulación de } \\
\text { "pronunciamientos", es que previo a las reuniones, se circula información en la Red } \\
\text { para conocimiento de los temas a tratar y sobre los cuales se habrá de tomar alguna } \\
\text { decisión. La interconexión depende de la relación si es fuerte o débil dependiendo del } \\
\text { "peso" del ambientalista independiente y/o de la agrupación ambiental que promueve } \\
\text { algún punto de acuerdo para ser considerado como "pronunciamiento". }\end{array}$ \\
\hline $\begin{array}{l}\text { Distribución de poder } \\
\text { entre actores en la red }\end{array}$ & $\begin{array}{l}\text { Hasta ahora y después de seis reuniones de la Red, se mantiene la actividad del } \\
\text { Secretariado, a través del cual se procura evitar asimetrías de relaciones y por tanto, } \\
\text { de dependencia entre los actores. }\end{array}$ \\
\hline
\end{tabular}

Fuente: Adaptación propia con base en Cruz (2008) y en el trabajo de campo.

Las redes ambientales por su temática de interés, tienen como característica el fortalecimiento de las relaciones entre sus integrantes, actuando sobre la base de una problemática concreta, más que la determinación de cierto número variables a atender, y en donde el esfuerzo termine por dispersarse. En este sentido, la posibilidad de desarrollo del turismo basado en la estructura de las redes ambientales, encuentra la posibilidad de consecución de acciones sistemáticas y organizadas a partir de la voluntad y disposición de los distintos actores.

Con base en lo anterior, es importante destacar que al interior de la REDAEM se considera que la problemática ambiental es muy seria, que el cambio climático comienza a mostrar las afectaciones que puede producir y que con el tiempo va a ser más fuerte, impactando al sector económico y a la estabilidad social, situación que permite ver la falta de compromiso como sociedad por hacer algo al respecto, en donde hasta ahora los gobiernos aparentan como que trabajan pero en realidad lo que están haciendo es perder un tiempo valioso que más adelante 
la sociedad y sus gobiernos se arrepentirán de no haber aceptado su responsabilidad. El sector social, particularmente las organizaciones de la sociedad civil, sí saben que el problema va en aumento pero no pueden hacer nada porque cada quien hace su lucha aisladamente, sin fuerza, por lo que el proceso de conformar una red de ambientalistas se centró en brindarse apoyo mutuo, en donde los intereses por pertenecer a la red generalmente son vistos como la oportunidad de obtener un beneficio propio, aspecto que como lo comenta Mejía Alonso (2012), no está mal, siempre y cuando también el grupo o individuo, comparta su experiencia con los demás grupos, individuos y sociedad en general.

Así, la conformación de asociaciones, grupos y comités en el ámbito municipal, pasando por consejos asesores, de cuenca y comisiones, las mesas de trabajo en el nivel estatal, hasta consejos consultivos para el desarrollo sustentable en el nivel federal, ha marcado un proceso de participación de la sociedad civil en la vida y desarrollo del país. A pesar de esos esfuerzos, con la puesta en marcha de acciones encaminadas a la sustentabilidad, pocos resultados tangibles se han producido. El punto crucial es que muchas de las observaciones que la propia sociedad establece, tiene que pasar en última instancia por el visto bueno del gobierno.

El peso de la REDAEM en cuanto al impulso de políticas públicas en materia de turismo será relevante en la medida en que como red interorganizacional participe constantemente en la toma de decisiones de las acciones $\mathrm{u}$ objetivos planteados en los planes, programas y proyectos gubernamentales; y más aún, en la conformación de una Red de Turismo Estatal que también agrupe a los principales promotores de la actividad turística en la entidad, y que sirva como un mecanismo real de participación de las comunidades locales, prestadores de servicios y visitantes en la promoción de mejores prácticas ambientales particularmente en las áreas naturales protegidas.

\section{Conclusiones}

El análisis de las redes sociales como se ha observado, no es una visión reciente. Ya desde el siglo pasado se mostraba como una perspectiva para el estudio del entramado de vínculos entre individuos. Así, en el marco de los nuevos movimientos sociales y con el 
desenvolvimiento de una participación social más decidida a cambiar el rumbo de sus condiciones de salud, educación, vivienda, laborales, ambientales e incluso de esparcimiento, y aunado al desarrollo de enfoques teóricos y metodológicos como el de sistemas complejos y de políticas públicas, las redes sociales como objeto de estudio han prosperado hasta establecerse como un paradigma cada vez más recurrente para analizar, explicar e incluso modificar las situaciones que inciden en la interrelación sociedad civil-gobierno.

En este sentido, las redes sociales desde una perspectiva de los sistemas complejos, se definen como las estructuras que basadas en las relaciones de sus integrantes, se acercan a la solución de problemáticas diversas, que permiten conectar los subsistemas natural y antrópico a partir de esquemas de interdependencia e interdisciplinariedad y en donde se promueven relaciones horizontales, así como la articulación público-privado-social.

En particular, el turismo como una actividad relevante en la economía del país, de la entidad y del municipio, genera una cantidad importante de beneficios pero también de impactos negativos en el ambiente. Derivado de ello, las áreas naturales protegidas como reservorios de la biodiversidad, de la captación de agua, bióxido de carbono y liberación de oxígeno, además de otros servicios ambientales aprovechados por el turismo como el paisaje, la tranquilidad, la nieve en algunos periodos, resultan espacios que requieren ser atendidos no solamente desde la promulgación de decretos o planes, sino a partir de la participación de la sociedad civil que organizada en redes ambientales, apoye y guíe a las comunidades locales a la conservación y aprovechamiento armónico de los recursos con que cuenta. Al respecto y considerando la ausencia de un concepto de red ambiental de políticas públicas, que soporte teórica y metodológicamente su análisis desde los sistemas complejos, más allá de su concepción como estructura, su contribución permitirá, concretamente en el proceso de acercamiento a la problemática turística en las áreas naturales protegidas, establecer nuevos enfoques de gobernanza fundamentada en el intercambio de experiencias, en la flexibilidad y horizontalidad así como en la generación de políticas públicas, resaltando su particularidad como una red interorganizacional real, consistente y congruente más que con los intereses económicos y políticos de algunos actores y sectores, con las necesidades de las comunidades locales y visitantes. 
Derivado de las entrevistas realizadas a los informantes clave, y considerando que las condiciones en las cuales se ha manifestado el turismo en el "Nevado de Toluca" no han sido las óptimas, debido a la falta de un programa para su desarrollo; de la ausencia de organización de las comunidades locales; del poco interés del gobierno, sector educativo y empresarial para el impulso de modalidades de turismo de bajo impacto; aunado al trabajo aislado de la sociedad civil organizada; es que alternativas como la conformación de redes ambientales de políticas públicas, devienen en la posibilidad de generar acciones encaminadas a ordenar aquello que hasta la fecha se ha presentado de manera anárquica.

Las redes ambientales de políticas públicas como enfoque alternativo enfocado a la generación de pronunciamientos que se transformen en políticas públicas dirigidas al impulso de un turismo más armónico con el ambiente, requiere asimismo retomar de experiencias anteriores, como la pretendida por el gobierno estatal a través del extinto Consejo Asesor del "Nevado de Toluca", la lección de involucrar en los proyectos y decisiones sobre temas ambientales y de turismo en particular, principalmente a la comunidad local y a la sociedad civil organizada, sectores que generalmente solo son consultados para avalar y en todo caso justificar ciertas acciones de beneficio para el gobierno en turno.

Concretamente, la propuesta de red ambiental de políticas públicas plantea alcances y limitaciones para el estudio del turismo en áreas naturales. Con respecto a los alcances se identifican cuatro puntos básicos: a) el espacio físico que abarca el estudio de una problemática concreta y que representa el recorte de la realidad; b) los actores, es decir el total de individuos y/o grupos que formarán parte de una red; c) las actividades a desarrollar, lo cual implica la agenda de acciones y d) el tiempo que se establece para lograr los objetivos planteados.

Referente a las limitaciones, hay que considerar que la conformación de redes no es una tarea sencilla. Es un proceso que requiere de consensos, de convencimientos, así como de una guía que defina el rumbo del colectivo. Aspectos como la horizontalidad, la cooperación, la complementariedad y el compromiso, se convierten en ejes que los distintos actores que intervienen en la integración de la red deberán de fortalecer en el entendido de minimizar riesgos derivados tanto de factores internos como la diversidad de objetivos y metas, la inclusión-exclusión o el protagonismo; así como de variables externas como la presión 
gubernamental, la unilateralidad, la debilidad del tejido social, la corrupción, entre otras, que sin lugar a dudas amenacen su estabilización, su continuidad y por consiguiente el desarrollo de una actividad turística armónica.

Finalmente, vale denotar que uno de los puntos que se requiere tener en todo momento presente, es el que se refiere al status de los pronunciamientos, es decir, que estas iniciativas como uno de los propósitos medulares de la red, no se queden precisamente en retórica y que realmente trasciendan hasta tornarse en políticas públicas.

La necesidad de la formación de la red; la búsqueda de métodos apropiados para su estudio; la interacción investigador/actor; el uso de los métodos cualitativos y participativos, así como la posibilidad de estudio de las redes incorporando las contribuciones de los análisis de sistemas complejos, de políticas públicas y turismo, son tan sólo algunas de las incontables dificultades y por tanto desafíos a enfrentar en el enfoque de redes sociales y particularmente en el de redes ambientales. Este reto se establece como una forma para la comprensión del mundo actual, de las relaciones que en él se dan, intentando innovar al introducir conceptos que permitan comprenderlo en su complejidad. En este sentido, la consideración de las redes ambientales vinculadas a la actividad turística en áreas naturales protegidas, implicará una importante apuesta a discurrir en el campo teórico y metodológico, en el que este trabajo representa una de las primeras aproximaciones para su abordaje.

\section{Referencias}

ADLER LOMNITZ, L. Redes sociales, cultura y poder. Ensayos de antropología Latinoamericana. México: FLACSO, 2001.

ARANDA SÁNCHEZ, J. M. Constructivismo y análisis de los movimientos sociales. En Ciencia, Ergo Sum. Vol. 9, núm. 3, noviembre, Toluca, México: UAEM, 2006. p. 218-230

ARANDA SÁNCHEZ, J. M. Construcción del movimiento ambientalista en México: 1980-2005. Toluca, México: UAEM, 2002.

ÁVILA, P. Política ambiental y organizaciones no gubernamentales en México. José Luis Méndez (Coord.). En Organizaciones Civiles y Políticas Públicas en México y Centroamérica. México, D. F.: Academia Mexicana de Investigación en Políticas Públicas, A. C., 1998.

BAZÚA, F.y VALENTI, G. Hacia un enfoque amplio de política pública. En Revista de Administración Pública. Núm. 84, México: Instituto Nacional de Administración Pública, A. C., 1993. 
CARDOZO CABAS, G. Historia del concepto de red social. Bogotá, Colombia: Unidad de Investigación Universidad Santo Tomás, 2009.

CEBAllos, G. Propuesta de recategorización y redecreto del Parque Nacional Nevado de Toluca. Secretaria del Medio Ambiente, Toluca, México: Gobierno del Estado de México, 2010.

CONANP. Plan de Conservación y Manejo del Parque Nacional Nevado de Toluca. Toluca, Estado de México: 2008.

CRUZ JIMÉNEZ, G. Evaluación del efecto ambiental causado por la actividad turística en el Parque Nacional Nevado de Toluca. Tesis (Licenciatura en Turismo), Facultad de Turismo, Toluca, México: UAEM, 1997.

CRUZ JIMÉNEZ, G. El turismo como elemento de conflicto y acuerdo en las redes de política pública de Ixtapan de la Sal, México. Tesis de Doctorado en Ciencias Sociales, Zinacantepec, México: El Colegio Mexiquense, A. C., 2008.

DE LA TORRE PADILLA, O. El turismo fenómeno social. México: FCE, 1980.

ESPINOSA CASTILLO, M. (coord.). Tendencias de investigación turística a principios del Siglo XXI., México, D.F.: Instituto Politécnico Nacional 2007.

FLICK, U. Introducción a la Investigación Cualitativa. España: Morata, 2007.

FRANCO MASS, S., et al. Evaluación multicriterio de los recursos turísticos: Parque Nacional Nevado de Toluca-México. En Estudios y Perspectivas en Turismo. Vol. 18, núm. 2, 2009. p. 208226

GARCÍA, R. El conocimiento en construcción. De las formulaciones de Jean Piaget a la teoría de sistemas complejos. España: Gedisa, 2000.

GARCÍA, R. Sistemas Complejos. Conceptos, método y fundamentación epistemológica de la investigación interdisciplinaria. Barcelona, España: Gedisa, 2006.

GARRIDO, F. J. "El análisis de redes en el desarrollo local”. Prácticas locales de creatividad social. España: El Viejo Topo, 2001. pp. 67-89.

GUZMÁN, J. M., et al. Redes de apoyo social de las personas mayores: marco conceptual. Notas de Población, 29 (77), p. 35-70, 2003 www.eclac.cl/publicaciones/xml/0/14200/lclg2213_p2.pdf, 2003.

HERNÁNDEZ SAMPIERI, R., et. al., Metodología de la Investigación. México: Mac Graw-Hill Interamericana, 2010.

JAFARI, J. El turismo como disciplina científica. Política y Sociedad. Vol. 42, núm. 1, Universidad Complutense, Madrid: 2005. p. 39-56

LGEEPA. Ley General del Equilibrio Ecológico y Protección al Ambiente, México: 1988.

MASERA, D. Hacia un consumo sustentable. La transición hacia el desarrollo sustentable, perspectivas para América Latina y el Caribe. México: SEMARNAT, INE, Universidad de Guadalajara, 2002.

MORALES, A. y SOJO, C. Concertación insostenible: Estado y organismos no gubernamentales en la política costarricense de desarrollo sostenible. En Organizaciones Civiles y Políticas Públicas en México y Centroamérica, José Luis Méndez (Coord.), México, D. F.: Academia Mexicana de Investigación en Políticas Públicas, A. C., 1998. 
MOTTA, R. Las redes sociales informales y la búsqueda de la ecuación interactiva entre la toma de decisiones locales y la responsabilidad de la gobernabilidad global. Dabas, E. y D. Najmanovich (comp.), En Redes. El lenguaje de los vínculos. Buenos Aires: Paidós, 1995.

MUÑOZ ROA, P. Influencia de los factores comunitarios en la resiliencia: estudio realizado en hogares urbanos de la zona central de la República Mexicana, beneficiarios del programa de desarrollo humano oportunidades. Tesis de Doctorado, México, D. F.: Universidad Iberoamericana, 2012.

NATERAS GONZÁLEZ, M. Las políticas públicas, ¿discurso o realidad?. En Espacios Públicos. Vol. 9, núm. 017, febrero, Toluca: UAEM, 2006. p. 252-274

ORGANIZACIÓN MUNDIAL DEL TURISMO, OMT. Agenda para planificadores locales: Turismo sostenible y gestión municipal. Madrid, España: 1999.

PARSONS, W. Políticas públicas, una introducción a la teoría y a la práctica del análisis de políticas públicas. México, D. F.: FLACSO-México, 2007.

PÉREZ ANDRÉS, C. Sobre la metodología cualitativa. En Revista Española de Salud Pública. Vol. 76, núm. 5, septiembre-octubre, España: 2002. p. 373-380

PÉREZ-RAMÍREZ, et. al. Turismo e identidad de resistencia La oposición local a proyectos turísticos en el Parque Nacional Nevado de Toluca, México. En Estudios y Perspectivas en Turismo. Vol. 18, núm. 1, marzo: 2009. p. 36-52

PORRAS, F. Introducción. Gobernanza y redes de política pública en México. En Gobernanza y Redes de Política Pública en Espacios Locales de México. México, D.F.: Instituto Mora, 2012.

REQUENA SANTOS, F. El concepto de red social. En Revista Española de Investigaciones Sociológicas. Número 48, Universidad de Málaga: 1989. p. 137-152

RHODES, R. A. W. Understanding Governance: Policy Networks, Reflexivity and Accountability. Buckingham: Open University Press, 1997.

RIVOIR, A. L. Redes sociales: ¿Instrumento metodológico o categoría sociológica?. En Revista de Ciencias Sociales. Montevideo: F.C.U., 1999.

RODRÍGUEZ VILLASANTE, T. Las ciudades hablan. Caracas, Venezuela: Ed. Nueva Sociedad, 1994.

RODRÍGUEZ VILLASANTE, T. Redes y conjuntos de acción: para aplicaciones estratégicas en los tiempos de la complejidad social. En Política y Sociedad. Vol. 44, núm. 1, año 2007: 2006. p.125-140

RODRÍGUEZ WOOG, et al. Turismo alternativo: Un acercamiento crítico y conceptual. Serie Textos, núm. 1, México, D. F.: Nuevo Tiempo Libre, 1986.

SÁNCHEZ-BARRETO, R. F., et. al. La complejidad expresión de nuestro tiempo: el turismo desde los sistemas complejos. En Revista Cultur., núm. 01, febrero 2012, año 06, Ilhéus-Bahia, Brasil: Universidade Estadual de Santa Cruz, 2012.

SECTUR. Programa de turismo sustentable en México. México, D.F.: 2012

SERRANO BARQUÍN, R. Hacia un modelo teórico-metodológico para el análisis del desarrollo, la sostenibilidad y el turismo. En Economía, Sociedad y Territorio. Vol. VIII, núm. 26, Zinacantepec, México.: El Colegio Mexiquense, A. C, 2008. p. 313-356

TORRES, B. Las ONG: avances de investigación sobre sus características y actuación. En Organizaciones Civiles y Políticas Públicas en México y Centroamérica. José Luis Méndez (Coord.), México, D. F.: Academia Mexicana de Investigación en Políticas Públicas, A. C., 1998. 
UAEM. Foro internacional sobre la gestión de áreas naturales protegidas. Toluca, México: 2013.

VIGLIANI, S. Reseña de Las aguas celestiales. Nevado de Toluca. Luna et al. (coords.). En Cuicuilco. Vol. 16, núm. 45, enero-abril, México, D.F.: 2009. p. 267-275

WELLMAN, B. Structural analysis: from method and metaphor to theory and substance. En Social Structures: A Network Approach. Cambridge University Press, Ed. Barry Wellman y S. D. Berkowitz, 1998.

\section{Entrevistas}

DE LA ROSA, Isaías. Ambientalista independiente. Entrevista realizada el 24/07/10

HERNÁNDEZ GARCÍA, Angélica. Grupo Ambiental Zarframex. Entrevistas realizadas el 23/10/2010 y el 25/05/12.

MANDUJANO ÁLVAREZ, Luis Miguel. Director del Parque Nacional Nevado de Toluca. Entrevista realizada el 24/11/11

MEJÍA ALONSO, Francisco. Red de Ambientalistas del Estado de México. Entrevista realizada el $1 / 06 / 12$.

MONTOYA, SALOMÓN. Personal de la Comisión Estatal de Áreas Naturales y de la Fauna (CEPANAF). Entrevista realizada el 30/05/11

PLIEGO CASTIL, PEDRO. Red Acción Ambiente. Entrevista realizada el 12/03/09

REYES PIZA, Eduardo. Personal de la Dirección de Turismo del H. Ayuntamiento de Toluca. Entrevista realizada el 17/08/12

Recebido em: 12/04/2013 ( $1^{\text {a }}$ versão) 14/11/2013 (última versão)

Aprovado em: 08/01/2014 